\title{
O conflito entre a dinâmica de ocupação e a qualidade ambiental em áreas de reservatório - o caso do lago de Itaipu
}

\author{
Leila Regina Youssef Thaumaturgo ${ }^{\text {; }}$; Silvio Jorge Coelho Simões ${ }^{2}$; \\ Isabel Cristina de Barros Trannin ${ }^{3}$ \\ ${ }^{1}$ Doutoranda no Programa de Pós-Graduação em Área de Transmissão e Conversão de \\ Energia da Universidade Estadual Paulista Júlio de Mesquita Filho (UNESP) \\ E-mail: 1ry2004@ hotmail.com \\ 2 Professor do Programa de Pós-Graduação em Área de Transmissão e Conversão de \\ Energia da Universidade Estadual Paulista Júlio de Mesquita Filho (UNESP) \\ E-mail: simoes@feg.unesp.br \\ ${ }^{3}$ Professora do Programa de Pós-Graduação em Engenharia Civil e Ambiental da \\ Universidade Estadual Paulista Júlio de Mesquita Filho (UNESP) \\ E-mail: isatrannin@uol.com.br
}

\begin{abstract}
Resumo
O objetivo deste trabalho é apresentar um estudo introdutório sobre os efeitos do processo de ocupação tanto em áreas urbanas quanto rurais - sobre a qualidade ambiental e a preservação ambiental nas áreas de reservatório tomando, como exemplo, o caso da Hidrelétrica de Itaipu e dos dezesseis municípios lindeiros banhados pelo reservatório. O crescimento populacional na região pode ser considerado acima das outras regiões do país mesmo levando em conta as altas taxas de urbanização no período de 1970 até o presente. O trabalho aponta que o processo de gestão e o plano de manejo da Usina Hidrelétrica de Itaipu não consideraram o intenso processo de expansão urbana e suas conseqüências ambientais. Entre estas conseqüências destaca-se o problema do assoreamento do reservatório que atinge níveis bem superiores ao previsto na implantação da Usina.
\end{abstract}

Palavras-chaves: processos migratórios; reservatórios de hidrelétricas; qualidade ambiental

Título em inglês: The effects of the human occupation on environmental quality of the hydropower reservoirs - The case of Itaipu lake

\begin{abstract}
The main goal of this work is to present an introductory study on the effects of the human occupation on environmental quality and preservation of a large Brazilian reservoir (Itaipu Hydropower Dam). Water quality of the reservoir has deteriorated significantly due to sixteen towns situated around the reservoir, which are responsible for different degradation processes. This work shows a conflict situation between the migratory policy of different Brazilian Governments and the environmental management plan of large hydropower. As an example, the high level of sediment yields in the basin could reduce dramatically the useful life of Itaipu reservoir.
\end{abstract}

Keywords: migratory process, hydropower reservoir, environmental quality

\section{Introdução}

A história da humanidade mostra a grande dependência do homem em relação às fontes energéticas. A energia eólica, solar e a provinda do fogo, já eram conhecidas nas populações primitivas. Com a revolução industrial, a energia gerada da combustão de madeira foi substituída pelo uso indiscriminado da energia gerada pela combustão fóssil (carvão mineral), causando a devastação de matas e florestas e grandes danos ao meio ambiente, com tamanha intensidade que o homem dificilmente, tem conseguido reparar.

Com o surgimento da energia hidrelétrica o homem passa a conhecer uma forma limpa de produção de energia a qual não está associada a produção de gases como, monóxido e dióxido de carbono, óxido de nitrogênio e resíduos radioativos produzidos pela queima do carvão mineral e do petróleo. Neste sentido a matriz energética brasileira tem se aproveitado dos grandes sistemas fluviais do país e cerca de $80 \%$ da geração de energia nacional é proveniente de hidrelétricas situadas nas mais diferentes regiões do Brasil. 
Entretanto este modelo energético, com a conseqüente criação de grandes reservatórios, foi dissociado das políticas que conduziram o processo de ocupação nacional como aquele que ocorreu entre 1934 e 1945, durante o Governo Getúlio Vargas, induzindo e estimulando a "marcha para o Oeste" para a Região Oeste do Paraná. A criação e a implantação da Usina Hidrelétrica de Itaipu, nos anos 70, não conseguiram avaliar e prever as possíveis interrelações entre a formação do lago e os processos migratórios tornando-se paradigmático desta política de dissociação entre a formação de grandes reservatórios e o processo de ocupação do território nacional.

Desta maneira, o objetivo deste trabalho é apresentar um estudo introdutório sobre os efeitos do processo de ocupação - tanto em áreas urbanas quanto rurais - sobre a qualidade ambiental e a preservação ambiental nas áreas de reservatório tomando, como exemplo, o caso da Hidrelétrica de Itaipu e dos dezesseis municípios lindeiros banhados pelo reservatório.

\section{Metodologia}

Inicialmente foram identificados dados e informações sobre a evolução histórica da implantação do reservatório e dos processos migratórios para a região Oeste do Paraná. A fonte de dados para esta pesquisa se constitui de diversos documentos a maioria deles inéditos.

Os dados ambientais constaram de diagnósticos e documentos obtidos junto a Hidrelétrica de Itaipu e das administrações municipais das cidades lindeiras ao lago de Itaipu. Também foram consultados documentos legais produzidos pelo Conselho Nacional de Meio Ambiente, IBAMA (2008).

Portanto, este estudo de caso é uma pesquisa de dados que investiga um problema atual dentro do contexto da vida real. De acordo com Santos (2004), alguns conceitos práticos são determinantes para a definição da metodologia de um trabalho.

"Uso e ocupação das terras" é um tema básico para um planejamento ambiental, porque retrata as atividades humanas que podem significar pressão e impacto sobre os elementos naturais. É uma ponte essencial para a analise de fontes de poluição e um elo importante de ligação entre as informações dos meios "biofísico e socioeconômico"....As informações sobre este tema devem descrever não só a situação atual, mas as mudanças recentes e o histórico de ocupação da área de estudo “.

\section{Resultados e Discussão}

\subsection{Evolução histórica do lago de Itaipu}

A política econômica do protecionismo da agricultura de Vargas não resistiu ao avanço da industrialização no País. O êxodo rural foi inevitável, as pessoas deixaram os campos e dirigiram-se às cidades em busca de uma melhor condição de vida. As cidades foram crescendo, rodovias foram construídas e muitas indústrias foram implantadas aumentando consideravelmente o consumo energético.

Em 1934, Vargas promulgou o Código de Águas que estabelecia a competência exclusiva do governo federal como poder concedente dos aproveitamentos hidrelétricos. Em 1939, foi criado o Conselho Nacional das Águas e Energia Elétrica, com o objetivo de aperfeiçoar a legislação na oferta da energia elétrica. (LEONARDO, 1998).

Neste período muitas cidades já eram servidas de energia elétrica e o Brasil contava com 783 hidrelétricas e 637 termelétricas, todas pertencentes a duas empresas estrangeiras - à Brazilian Traction Light \& Power Co com sede no Canadá e a American \& Foreign Power Co (Amforp), com sede nos EUA, que forneciam juntas um total de $1.044 .738 \mathrm{KW}$. As redes de 
transmissão de energia não atendiam à grande distância e a demanda de energia elétrica, que por sinal, estavam bem acima da capacidade de oferta da geração, prenunciando, já no início dos anos 40, uma situação de escassez de energia (LAMARÃO, 2003).

Acompanhando um pouco a história econômica do Brasil e o desenvolvimento urbano das duas maiores metrópoles brasileiras; Rio de Janeiro, a capital do país e São Paulo, a capital industrial, podemos entender a necessidade do suprimento eficiente e com produção em alta escala de energia para os dias de hoje, com critérios e métodos compatíveis na preservação do meio ambiente (LAMARÃO, 2003).

Após a Segunda Guerra Mundial, em 1945, o país passou a viver as ações geopolíticas da "guerra fria", onde desencadeou o processo de ocupação das novas "fronteiras agrícolas". Neste sentido, houve um incentivo por parte do Governo para a ocupação dos territórios considerados despovoados principalmente nas regiões do centro-oeste do país. O mecanismo que o Governo utilizou para povoar as áreas mais ocidentais do país foram os preços baixos da terra e a sua fertilidade principalmente no caso do oeste do Estado de Santa Catarina e do Paraná e sul do Mato Grosso do Sul, nos quais predominam a denominada "terra roxa" proveniente de derrames basálticos (ZAAR, 1998). O público alvo desta política de incentivo foi composto por trabalhadores agrícolas com propriedades inferiores as necessárias a sua reprodução, ou que se encontravam sem terras para cultivar. Neste período a população brasileira vivia em constantes migrações. Das principais rotas de trabalhadores agrícolas podemos encontrar a dos nordestinos, que durante todo o século deslocaram-se a vários pontos da Região Nordeste do país e os colonos descendentes de italianos e alemães do sul do Brasil, principalmente dos Estados do Rio Grande do Sul (RS) e de Santa Catarina (SC), bem como, os mineiros e os paulistas que passaram a colonizar, a partir da década de 1940, a região oeste dos Estados de SC e PR e a partir das décadas de 1960 e 1970, os Estados de Mato Grosso do Sul (MS), Mato Grosso (MT) e Goiás (GO) (ZAAR Z,1999).

A meta governamental de desenvolvimento nacional em ritmo acelerado exigiu a construção de várias usinas hidrelétricas. Entre elas, estão as usinas de Paulo Afonso I e II, a de Furnas, a de Cubatão e a de Mascarenhas de Moraes.

A explosão do setor industrial de São Paulo atingiu seu apogeu no início da década de 1970. No meado da mesma década, começa uma nova transformação devido à transferência das indústrias da metrópole (descentralização metropolitana), para novos pólos industriais localizados nas mais expressivas regiões, bem como no interior do próprio Estado de São Paulo.

A grande crise econômica mundial dos anos 80 tem como marco histórico; a decisão árabe de embargar as exportações de petróleo para o Ocidente durante a guerra árabeisraelense de 1973. A partir daí, o modelo de desenvolvimento, baseado na substituição de importações de bens industrializados, começa a decair, e o suprimento eficiente de energia passa a ser considerado uma das condições básicas para o desenvolvimento econômico do país. Para atender a demanda, começa então a corrida pela obtenção de energia em alta escala assim, os projetos para a construção das Usinas Termoelétrica; Hidroelétrica (Ilha Solteira, Tucuruí I e II, Paulo Afonso, Jupiá, Porto Primavera); Nuclear (Angra I e II) e de Extração de Petróleo (Petrobras), passou a fazer parte dos projetos prioritários do Governo Nacional (LEONARDO, 1998).

Para suprir as necessidades crescentes de energia deste período, foi idealizada a construção de uma usina hidrelétrica de grande porte, para isso se iniciaram estudos complexos que determinaram o local ideal do empreendimento. Optou-se então, pelo Rio Paraná, no trecho onde se localiza o município de Foz do Iguaçu no estado do Paraná divisa com Paraguai, devido sua formação geológica e seu volume de água. Sob um acordo firmado em abril de 1973 entre os governos do Brasil e do Paraguai para a construção da usina que 
produziria $12.600 \mathrm{Mw}$ de potência, equivalente a $75 \%$ da energia produzida em todo pais em 1973 (ITAIPU BINACIONAL, 2008).

No caso da implantação da Usina Hidrelétrica de Itaipu foi preciso modificar todo um conjunto do patrimônio natural do Rio Paraná para a construção do canal de desvio, da barragem e da criação do reservatório de $1.350 \mathrm{~km}^{2}$ de uma extensão de $170 \mathrm{~km}$, um grande prejuízo ambiental em prol do desenvolvimento. Da área inundada, 835 quilômetros quadrados encontram-se em território brasileiro, limitando a área de desapropriação até a curva de nível de 225 metros acima do nível do mar (ITAIPU BINACIONAL, 2008).

O espetáculo natural das Cataratas de Setes Quedas desapareceu do mapa quando o reservatório começou a encher processo este que demorou 14 dias para atingir a cota normal de 140 metros com um volume de 29 bilhões de metros cúbicos de água. Grandes áreas destinadas à agropecuária, fonte da economia da região, foram submersas segundo dados da Binacional Itaipu, 42.000 brasileiros desapropriados e indenizados, destes 38.000 residentes na área rural como também a velha cidade de Santa Helena que guardava em suas terras a história da formação do oeste paranaense (ITAIPU BINACIONAL, 2008).

Foz do Iguaçu até 1970 crescia gradativa e ordenadamente, chegando a uma população de apenas 33.966 habitantes. (PMFI, 2008). Ela não estava devidamente preparada para receber repentinamente uma população de mais de 30.000 operários com suas respectivas famílias vinda de cada canto do país para construção da usina. Juntos com os obreiros vieram novas estradas, hospitais, escolas, condomínios residenciais, grande variedade de comercio, hábitos e costumes diferentes da população local, enfim, tudo o que era necessário para atender á esta população que de veio longe para concretizar um sonho de uma nação. Para suprir as novas necessidades de moradia a Itaipu Binacional adotou medidas como a construção no espaço de três anos dos bairros denominados como Vila A, Vila B e Vila C. As vilas da Itaipu contavam com áreas verdes e espaços semi-públicos, onde os moradores podiam se relacionar. As ruas eram cuidadas e embelezadas pela administração da Itaipu, que criou um horto florestal para produzir: mudas de árvores de espécies nativas, flores e vegetação de forração que eram utilizados em todos os seus bairros, bosques e vias de acesso.

Estes bairros foram organizados respeitando uma separação de funções. A Vila "A" possuía um contexto diferente das demais, visto que sua comunidade era formada por diversos profissionais de nível técnico e superior. A Vila "B" abrigava os engenheiros e demais profissionais que ocupavam cargos de liderança dentro do quadro de funcionários da Itaipu. Esta vila tinha uma configuração rara para a época, por apresentar características como as de um condomínio fechado, porém, a intenção deste não se baseava na necessidade de segurança como acontece nos condomínios atuais, mas sim na separação social dessa comunidade. Na Vila "C" instalavam-se os chamados "barrageiros" que tinham a função de construir não só a barragem, mas também a infra-estrutura de todo o empreendimento. (ITAIPU BINACIONAL; 2008). Os bairros, construídos pela Itaipu, não foram suficientes para a grande demanda populacional e desencadeou a necessidade de abertura de 52 novos loteamentos motivados pelo crescimento da população. Esses loteamentos nem sempre possuíam condições adequadas de habitação e na maioria das vezes estavam muito longe do centro e implantados em áreas de preservação sem a devida infra-estrutura adequada de saneamento básico. Os novos habitantes eram obrigados a ocupar lotes desprovidos, muitas vezes, de qualquer benfeitoria enquanto que grandes áreas bem localizadas, servidas de energia elétrica, rede de esgoto, transporte coletivo, etc., permaneciam vazias. (PMFI, 2008).

Em meados da década de 1980, a Itaipu já não atraia mais trabalhadores, mas com o aquecimento da economia pelo comercio com o Paraguai, a cidade voltou novamente a se expandir formando agora algumas conexões entre o centro e os bairros até então isolados. Nesta década surgiram mais 74 loteamentos. (PMFI, 2008). 
Na década de 1990 o ramo imobiliário continuou expandindo-se e criando cada vez mais loteamentos, chegando a um total de 125 ao final da década. Sabe-se que existem atualmente cerca de 300 loteamentos em Foz do Iguaçu, e aproximadamente 31 favelas e invasões.

O Brasil não podia parar e de fato não parou. Novas cidades nasceram e a região se desenvolveu para se render ao um país em processo de globalização. A Usina Hidrelétrica de Itaipu em 1974 revolucionou a história do oeste do Estado do Paraná e com o inicio da geração de energia em 1984, começa a mudar a história do país (ITAIPU BINACIONAL, 2008).

A Usina teve quatro fases de construção.

\begin{tabular}{|c|c|}
\hline FASE I & $\begin{array}{c}\text { (1975 a 1978) - Escavação do canal de desvio, construção da barragem de enrocamento, } \\
\text { instalação do canteiro industrial e execução da estrutura de controle, das ensecadeiras } \\
\text { principais e do efetivo desvio do rio Paraná. }\end{array}$ \\
\hline FASE II & $\begin{array}{c}(1978 \text { a 1982) - Construção da barragem principal, barragem lateral direita, barragens de } \\
\text { terra e de enrocamento, vertedouro, casa de força do leito do rio e início das } \\
\text { montagens eletromecânicas principais. }\end{array}$ \\
\hline FASE III & $\begin{array}{c}(1982 \text { a 1986) - Fechamento das comportas da estrutura de controle de desvio, formação } \\
\text { de reservatório, abertura do vertedouro e início da operação das primeiras } \\
\text { unidades na casa de força do leito do rio. }\end{array}$ \\
\hline FASE IV & $\begin{array}{c}(1986 \text { a 1991) - Construção da casa de força do canal de desvio e conclusão das } \\
\text { montagens das unidades geradoras restantes (ITAIPU-2008). }\end{array}$ \\
\hline
\end{tabular}

Antes da formação do lago foram removidos do local a ser inundado materiais de interesse arqueológico e histórico e, durante o alagamento, foram retirados de barcos e lanchas centenas de espécies de animais na tentativa de preservação da fauna regional (ITAIPU, 2007).

A partir de 1991 com o desativamento do grande canteiro de obras para a construção da usina começa a ser implantado o projeto de recuperação e manutenção de áreas verdes nativas e a criação de reservas para garantir a preservação e recuperar a fauna regional. Foram reimplantados mais de 17 milhões de muda para a criação da mata ciliar do reservatório. Um Grande esforço para a recuperação da biodiversidade local, das microbacias hidrográficas e da preservação da memória regional (ITAIPU, 2008).

\subsection{Principais Problemas ambientais}

Como se pode observar a partir da Tabela 2, a região obteve um grande crescimento populacional das cidades lindeiras, a qual não foi prevista pelos idealizadores, arquitetos e engenheiros do Projeto de Implantação da Usina de Itaipu.

Em face disto não previram quais as consequiências de uma expansão urbana sem o devido planejamento urbano e gestão ambiental sem deixar de ressaltar que a Região Oeste do Estado do Paraná é responsável por boa parte da soja produzida no país. Para se manter o alto nível de produção, o solo tem que estar bem adubado e bem protegido das pragas que possa afetar a sua produção e tudo isto ocorre de forma impactante sobre a bacia hidrográfica da maior usina hidrelétrica do mundo.

O crescimento populacional na região pode ser considerado acima das outras regiões do país mesmo considerando as altas taxas de urbanização no país no período de 1970 até o presente. Um exemplo deste crescimento é o caso de Foz do Iguaçu que teve crescimento de quase $1000 \%$ no período de 38 anos (Tabela 2). 


\section{Tabela 2 - A população das cidades lindeiras}

\begin{tabular}{|l|c|c|c|c|c|}
\hline \multicolumn{1}{|c|}{ Município } & Fundação & $\mathbf{1 9 7 0}$ & $\mathbf{1 9 8 0}$ & $\mathbf{1 9 9 1}$ & $\mathbf{2 0 0 7}$ \\
\hline Foz do Iguaçu -(PR) & 1914 & 33.966 & 136.231 & 190.123 & 311.336 \\
\hline Santa Terezinha de Itaipu-(PR) & 1982 & - & - & 14.149 & 19.552 \\
\hline São Miguel do Iguaçu-(PR) & 1961 & 25.747 & 34.247 & 24.721 & 25341 \\
\hline Itaipulândia-(PR) & 1992 & - & - & - & 8.581 \\
\hline Medianeira-(PR) & 1960 & 31.142 & 49.361 & 38.665 & 38.397 \\
\hline Missal-(PR) & 1983 & - & - & 10.372 & 10.412 \\
\hline Santa Helena-(PR) & 1967 & 26.834 & 34.884 & 18.861 & 22.794 \\
\hline Diamante D'Oeste-(PR) & 1989 & - & - & 9.253 & 4.944 \\
\hline São José das Palmeiras-(PR) & 1989 & - & - & 5.596 & 3.873 \\
\hline Marechal Cândido Rondon-(PR) & 1960 & 43.776 & 56.210 & 49.430 & 44.562 \\
\hline Mercedes-(PR) & 1993 & - & - & - & 4.713 \\
\hline Pato Bragado-(PR) & 1993 & - & - & - & 4.631 \\
\hline Entre Rios do Oeste-(PR) & 1993 & - & - & - & 3.842 \\
\hline Terra Roxa-(PR) & 1961 & 38.273 & 25.215 & 19.820 & 16.208 \\
\hline Guaíra & 1951 & 32.875 & 29.190 & 30.00 & 28.683 \\
\hline Mundo Novo-(MS) & 1976 & - & 31.156 & 22.417 & 15.968 \\
\hline
\end{tabular}

Fonte: IBGE - Censos Demográficos 1970, 1980, 1991 e 2007. -

(www.sidra.ibge.gov.br/bda/tabela/protabl.asp? $\mathrm{z}=\mathrm{t} \& \mathrm{o}=22 \& \mathrm{i}=\mathrm{p} \& \mathrm{c}=202$ )

O aumento populacional na cidade de Foz do Iguaçu veio acompanhado do crescimento da malha urbana através de vários loteamentos, que não foram idealizados e planejados para depois se inserir ao município, apenas foram pensados para resolver problemas momentâneos.

As necessidades comerciais e políticas fizeram com que muitos bairros ficassem isolados do centro acarretando um alto custo nos investimentos de infra-estruturas. Entre os bairros e o centro formaram-se os bolsões vazios, que primeiramente trouxeram uma crescente especulação imobiliária.

Essas áreas também ficaram a mercê das invasões e favelizações, pois muitas famílias encontraram nesses espaços um local favorável para habitar, já que eram dotados de alguma infra-estrutura e localizados próximos ao centro.

Além disto, ocorreu durante este período o surgimento de outras cidades na mesma região como é caso de Santa Terezinha com quase 20.000 habitantes. Portanto, a região é constituída de uma grande malha urbana fragmentada sem possuir ainda um mínimo de integração para se constituir em uma região administrativa integrada.

O plano de manejo para as áreas ocupadas pela Usina e pelo reservatório não se estendeu ao uso e ocupação dos solos (urbano e rural) do seu entorno. O plano de manejo teve como objetivo colaborar para que a Usina Hidrelétrica de Itaipu cumpra com as metas estabelecidas na sua criação. Este plano, o qual segue as normas do IBAMA (2006), define objetivos específicos de manejo para cada Unidade de Conservação (UC), de maneira a orientar e subsidiar a sua gestão na melhoria da vida útil do reservatório para uma maior produção de energia.

Os procedimentos técnicos de criação do reservatório estabeleceram uma vida útil de aproximadamente 200 anos, a determinados níveis de assoreamento do lago (ITAIPU, 2008). $\mathrm{O}$ assoreamento, porém, tende a crescer em taxas maiores do que aquelas previstas em face do acelerado crescimento das cidades o que aumenta, de forma preocupante, o volume de sedimentos que chegam ao lago. Se juntamente com o aumento do assoreamento ocorrem níveis elevados de poluição da água (particularmente devido a ausência de tratamento de esgoto na maior parte das cidades lindeiras) este processo de degradação termina afetando diretamente as turbinas aumentando significativamente o custo de manutenção. 
Portanto, o lago de Itaipu sofre diretamente o impacto das atividades econômicas de 16 municípios localizados no entorno do reservatório. Antes era a usina que provocava impacto sobre a região; agora é o uso inadequado da terra e da água que podem provocar danos desastrosos a todo este complexo formado pela usina hidrelétrica e pelas cidades lindeiras. Este processo de degradação está longe de ser pequeno: a bacia hidrográfica na qual se insere o lago de Itaipu é formada por treze sub-bacias alimentadas por mais de 1500 nascentes cuja qualidade precisa ser preservada a partir de uma visão de gestão ambiental que considere a região como um grande complexo integrado.

\section{Considerações finais}

Este trabalho procura avaliar, qualitativamente, os impactos do processo migratório acelerado (tanto urbanos como rurais) sobre uma região onde foi implantado um grande reservatório (no caso Itaipu). O trabalho aponta que o processo de gestão e o plano de manejo da Usina Hidrelétrica de Itaipu não consideraram o intenso processo de expansão urbana e suas conseqüências ambientais. Entre estas conseqüências destaca-se o problema do assoreamento do reservatório que atinge níveis bem superiores ao previsto na implantação da Usina.

$\mathrm{Na}$ continuidade desta pesquisa pretende-se obter dados quantitativos de parâmetros ambientais e indicadores como ferramenta que possibilitem compreender e melhor avaliar os efeitos da expansão urbana sobre a qualidade da água e do solo assim como o comprometimento da produção de energia da Usina Hidrelétrica de Itaipu.

\section{Referências}

IBAMA. Instituto Brasileiro do Meio Ambiente e dos Recursos Naturais Renováveis. Município de Santa Terezinha de Itaipu. Disponível em:

$<$ http://www.ibama.gov.br/parna_iguacu/index.php?id_menu=120/> Acesso em: 31 de agosto de 2008.

ITAIPU BINACIONAL. Nossa história. Disponível em :

</http://www.itaipu.gov.br/?q=node/356/> Acesso em: 21 de agosto de 2008.

IPARDES. Instituto Paranaense de Desenvolvimento Econômico e Social. Oeste Paranaense: Especificidades e Diversidades: Vários Paranás. Curitiba, 2008.

LAMARÃO, S.T. Energia elétrica como campo de pesquisa. Historiografia no Brasil. N 8. Cidade do México, 1998.

LEONARDO, H.C.L. Indicadores de qualidade do solo e água para a avaliação do uso sustentável da microbacia hidrográfica do rio Passo Cue, região oeste do Estado do Paraná. Tese de Mestrado,SP, 2003.

PMFI.Prefeitura Municipal de Foz do Iguaçu. Plano diretor. Disponível em: $<$ /http://www2.fozdoiguacu.pr.gov.br/Portal/Pagina.aspx?Id=176.Acesso 15 de agosto de 2008 . SANTOS. R.F. "Planejamento Ambiental: teoria e prática", São Paulo, Ed Conceito, 2004.

ZAAR, M. H. A Produção do Espaço Agrário: da colonização, à modernização e formação do Lago de Itaipu. Cascavel/PR: Edunioeste, 1999,148p. 